\title{
Working with Nonprofit Organizations in Community Settings: Preparing your Organization to Work with Volunteers
}

Elizabeth B. Bolton and Anna Guest-Jelley

\section{Developing the Policies and Procedures}

Policies and procedures have a relationship similar to goals and objectives. Policies apply to everyone in an organization and they establish clear guidelines and consequences. Further, they relate to the organization's mission and vision. Procedures, on the other hand, describe how to do things, such as how to implement policies, or manage the organization (Graff, 2001a). Preparing policies and procedures for the organization's work with and utilization of volunteers is an important first step.

It is increasingly important to have written volunteer management policies and procedures. This is because volunteer work is becoming more and more important-and complex. Nonprofits should think of their volunteers like unpaid employees, and treat them as such. Employees would not join an organization without some form of interview and orientation, and neither should volunteers today.

\section{Policy}

A written policy is a form of risk management, and managing risk is a key reason to have policies in place that pertain specifically to volunteers. If you have policies in place to eliminate or alleviate risks associated with volunteers, then you will have better informed volunteers and stakeholders. You will also know what to do should a problem arise because you have already considered and addressed possible risks associated with the organization. There are four functions that policies serve in volunteer programs that your organization can begin to consider and develop (Graff, 2001a, p.793):

1. Policies as risk management

2. Policies as values and belief statements

3. Policies as rules

4. Policies as program improvement tools

1. This publication is FCS9263, one of a series of the Department of Family, Youth and Community Sciences, Florida Cooperative Extension Service, Institute of Food and Agricultural Sciences, University of Florida. First published: June 2009. Reviewed June 2012. Please visit the EDIS Web site at http://edis.ifas.ufl.edu.

2. Elizabeth B. Bolton, Ph.D., professor of Community Development, Department of Family, Youth and Community Sciences; Florida Cooperative Extension Service; Institute of Food and Agricultural Sciences; University of Florida; Gainesville, Florida 32611 - 0310; and, Anna Guest-Jelley, MFYCS, MA, director of Violence Prevention Program, Peaceful Paths Domestic Abuse Network, also of Gainesville, FL. 
Possible topics for volunteer management policy include the following (Graff, 2001a, p. 804):

- Volunteer screening

- Recruitment

- Anti-discrimination

- Crossing picket lines

- Probation

- Recruitment of minors

- Volunteer-Paid staff relations

- Confidentiality

- Sexual Harassment

- Conflict of Interest

- Discipline

- Dismissal

- Immediate dismissal

\section{Recruitment Procedure}

As you develop your policy, procedure will follow. One important area for volunteer management procedure is recruitment.

Every nonprofit organization should have several recruitment procedures in place for the programs to which volunteers can contribute. These procedures will aid all stakeholders in understanding the role of volunteers in the organization-including the volunteers themselves! It also helps both the volunteer and the volunteer manager to decide if the volunteer is a good fit with the organization. Some procedures for the organization to consider follow (Graff, 2001b):

- List of requirements/Job description - No one wants to take a job without understanding what is expected of him or her, and that includes volunteers.

- Application Form - This can be similar to an application for paid employees, and cover any information the organization can legally ask: identifying information, availability, reason for volunteering, relevant experiences, references, etc.

- Interview Form - A written interview form will allow the volunteer manager to explore the volunteer's attitudes, perspectives, and issues more in-depth. Do not forget that interviews can be more than oneon-one; they can also include more than one interviewer, or more than one candidate.

- Qualifications Checks - This involves obtaining proof of qualifications from candidates. Especially if the qualifications are necessary to the job, ask for proof. Some qualifications checks may include: valid driver's license; valid auto insurance; a professional license, certificate, or academic degree; proof of immunization; background security checks; driver's records checks; and, in some cases, credit checks.

- Acceptance and Rejection Letters - These formal letters provide a level of clarification to the volunteer experience. The acceptance letter can convey more information about the volunteer's future work and the organization's excitement about working with him or her. The rejection letter should be brief but polite.

- Record of Service - As the organization recruits and retains volunteers, it is useful to maintain a record of service for each one. This way, both the volunteer and the organization will know exactly what work the volunteer has done and when. 


\section{Introducing and Orienting the Volunteer to the Organization}

After volunteers have been recruited and accepted, an orientation should be provided. Orientation can be either a formal or an informal procedure. How your organization conducts the orientation will be a key element in the successful utilization of the volunteer. An orientation that describes the expectations of the volunteerand those of the organization-will help everyone involved clarify the volunteer-organization relationship.

\section{Benefits to the Volunteer}

A good beginning for an orientation is to emphasize to the volunteer the benefits that he/she should expect from their participation, the benefits to the community at large, and what volunteer service means to the organization. Certainly, volunteers benefit when they share their time and talents to reach others. According to the Implications of Volunteerism for Extension study (Steele and Henderson, 1985), volunteers gain these benefits:

- information usable in other situations

- increased skill in working with people

- $\quad$ satisfaction from helping

- better understanding of their community

- shared interests

- opportunity to develop talents

- new friendships

Plus, there may be benefits that are unique to the volunteer experience with your organization.

\section{Benefits to the Organization}

The organization benefits from involvement of volunteers because the resources of the organization are multiplied through their work. Additional benefits include potential board members that might come from program volunteers. The tasks that volunteers perform and the duties they carry out are several and varied. Without volunteers, most nonprofit organizations would not be able to survive.

\section{Benefits to the Community}

Communities also benefit when volunteers are involved in nonprofit organizations. Individual community members reached by the volunteer gain these benefits:

- information

- new ideas and help with problems

- greater confidence in themselves

- friendship and support

Communities at large gain:

- more leaders,

- greater cohesion among neighborhoods,

- increase in trained volunteers, and

- opportunities for its citizens that did not previously exist. 


\section{Other Orientation Information}

Following the explanation of benefits, there are some general elements that should be covered in a volunteer orientation event or program:

1. A job description for the volunteer teacher; although described during the recruitment phase, the actual job description should be covered again, a copy given to the volunteer, and a copy included in the volunteer file maintained by the organization.

2. An explanation of the institutions which the volunteer represents through his/her teaching.

3. Policies and procedures that relate to the work the volunteer is entrusted to do.

4. The general code of ethics or conduct which the volunteer is expected to follow when dealing with clientele and working with other staff members and volunteers.

5. The organizational rules for safety, dress code, attendance and punctuality, health, etc.

6. Expense reimbursements, if applicable.

7. Requirements for reporting and record keeping.

\section{Orientation Checklist for the Nonprofit Volunteer}

\section{Explain the work of the Nonprofit Organization.}

a. Indicate volunteer's relationship within the particular program unit

b. Explain relation of the volunteer's work to that of others

c. Tell to whom volunteer reports and who, if anyone, reports to the volunteer

2. Show volunteer physical layout and available facilities.

a. Show volunteer own work area or teaching room, etc.

b. Show volunteer classrooms, elevators, rest rooms, water fountain, etc.

c. Discuss eating facilities, coffee machines, etc.

\section{Introduce volunteer to other staff.}

a. Indicate to each, the new volunteer's position

b. Briefly mention duties of each person introduced

4. Orient the volunteer to office management and operations.

a. Explain office set-up, files, records, etc.

b. Show volunteer telephone and mail operations

c. Share "criteria for volunteer self-evaluation"

d. Discuss hours of work, punctuality, good attendance, etc.

e. Explain any unusual working conditions, hazards, etc.

f. Explain lunch and break periods 


\section{Explain travel information to volunteer, if applicable.}

a. Discuss liability insurance coverage

b. Valid driver's license

c. Travel regulations, reimbursement procedures

\section{Explain necessity for the training programs.}

a .Explain training program and goals for volunteers

b .Discuss records to be kept

7. Inform volunteer on position responsibilities (some of these steps are covered as part of the training program; Checklist is provided to indicate they have been done).

a. Give volunteer current position description.

b. Discuss individual duties and responsibilities

c. Explain quality and quantity requirements and establish goals and objectives

d. Give step by step instruction in all aspects of the job

e. Indicate availability of resources and other help when needed

f. Provide learning aids and procedural manuals

h. Explain relationship to other agencies

i. Stress security of confidential information and public trust

8. Discuss need for record keeping and how it is done.

9. Discuss volunteer recognition programs, if applicable.

10. Follow-up.

a .Check progress often during first few days or weeks

b. Encourage questions and answer them fully

c. Make corrections tactfully and give encouragement.

Name of Volunteer:

Supervisor/s Signature(s):

Date :

Adapted from Smith, C.E. (1981). Orientation checklist for supervisors of volunteers. In Stout, P.E. (Ed.). Maximizing volunteers in program delivery. (pp. 28-29). Cornell University, New York: The New York State Colleges of Agriculture and Life Sciences and Human Ecology. 


\section{Providing Training for the Volunteer}

Orientation is a good time for training events. These events could be teaching volunteers what they need to know about an organization or how to do something for the organization. There are several different aspects to consider as you develop training events for the organization's orientation (Volunteer Development Agency, 2006).

\section{What will be taught?}

The first goal is to identify the content of the training. For example, will you be teaching administrative skills, teaching skills, content skills, etc.? Each training event should take into consideration the basic tenets of adult education since the majority of your volunteers will most likely be adults.

\section{What's different about adult education?}

Adults differ from younger learners in many ways. The most commonly agreed upon differences are in motivations to learn; need for hands-on, collaborative, and immediately applicable learning; the experience adults bring to learning situations; and time constraints. If the person in charge of planning the training event works to incorporate the needs of the adult learner into the event, they can expect more positive results (Boone, Safrit, \& Jones, 2002).

\section{Who will teach it?}

Identify the person or persons who will conduct the training event(s). Will the trainer be a member of the organization or will it be an outside expert? The person who trains the volunteer has a major responsibility to the organization and that role should be clearly defined.

\section{How will it be taught?}

Make the course content consistent with the principles of adult education and content delivery appropriate for your adult learners. Both of these will have bearing on how the course will be taught. Will it meet one time or several times? Will it be individual or group training? Will it involve a manual to read, a class? The most important consideration here is to attempt to involve the adult learners in decisions about how the course content will be delivered. While this is not always possible, it will make the adult learners more receptive to the content.

\section{How will you know the volunteer has mastered it?}

As you prepare the course, you should simultaneously consider the form of evaluation you will need after it. This can be as simple as self-evaluation, or you may need something more complex, depending on the skill being taught and the clients with whom the volunteers will be interacting.

\section{Record of Service}

The training event should be incorporated into the volunteer's record of service. A permanent file should be kept on each volunteer just as if they were a paid employee. While that may seem demanding on the part of the organization, there are advantages in doing so. The record of service will provide valuable information for the organization as well as for the volunteer if $\mathrm{s} /$ he should ever need documentation of hours worked, assignments, performance, etc. 


\section{Evaluation and Recognition of Volunteers}

\section{Evaluation}

Conducting periodic evaluations of your volunteers can yield many benefits. These evaluations can be either process- or outcome-based (or both). Process-based evaluations focus on the how-to: the steps volunteers engage in to either become volunteers or do their jobs. Outcome-based evaluations focus on the end result: becoming volunteers and/or the job(s) the volunteers accomplish. Both parties can feel a sense of accomplishment and ownership in the volunteer program by conducting evaluations because all stakeholders will know the results of the program and can then have a say in any necessary changes that arise as a result (Bradner, 2001).

\section{Organization and/or Volunteer Program Evaluation}

Examples of the two forms the evaluations may take follow. The organization may conduct evaluations of the volunteer program such as "client surveys of satisfaction with the volunteers, fund-raising reports before and after the program, new programs undertaken by the staff and its impact on the organization's ability to deliver services," etc. (Bradner, 2001). The volunteers may also complete evaluations on the volunteer program such as "surveys of volunteer satisfaction, and volunteer retention" (Bradner, 2001, p. 781). Both of these forms of evaluation may be helpful for completing a full picture of the volunteer program and its effectiveness for all stakeholders.

\section{Recognition}

Recognition of volunteers begins as soon as someone indicates interest in volunteering for the organization. It involves respecting the volunteers by "remembering people's names, their birthdays, their needs, and their motivations, and giving them honest compliments for their good work. Some of the ways people are motivated include: affiliation, achievement, personalized power, and socialized power" (Bradner, 2001, p. 779). If the recognition is tailored to the volunteer's motive for participation, the gesture is all the more effective.

\section{Formal and Informal Recognition}

Informal recognition can be compliments when others see volunteers doing good work. Formal recognition can cover a broad range of activities from volunteer recognition annual parties to giving out mugs, certificates, etc. Nonprofits debate the merits of recognizing a "best volunteer;" some choose to award a "most exciting new idea," "most interesting new project," "best team," and so forth; some choose not to single out anyone or anything as "best," instead recognizing volunteer contributions as a whole (Bradner, 2001, p. 780).

\section{Summary}

The information given here is applicable to all organizations that utilize the services of volunteers. A brief treatment of the various components of a volunteer management program are presented in this fact sheet but it should be noted that these are very abbreviated and additional information should be sought if your organization is developing or revising the volunteer management program. To get a real sense of the importance of volunteers in the U.S., refer to Independent Sector's recent statement estimating the value of volunteer time on an hourly basis as exceeding \$20.00/hour for 2008. 


\section{References}

Boone, E.J., Safrit, R.D. \& Jones, J. (2002). Developing Programs in Adult Education: A Conceptual Programming Model. $2^{\text {nd }}$ Edition. Prospect Heights, IL: Waveland.

Bradner, J.H. (2001). Volunteer Management. In T. D. Connors (Ed.), The Nonprofit Handbook Management (pp. 751-784). New York: John Wiley.

Graff, L.L. (2001a). Policies for Volunteer Programs. In T. D. Connors (Ed.), The Nonprofit Handbook: Management (pp. 785-814). New York: John Wiley.

Graff, L.L. (2001b). Volunteer Screening. In T. D. Connors (Ed.), The Nonprofit Handbook: Management (pp. 852877). New York: John Wiley

Independent Sector. Research: The value of volunteer time. Electronic retrieval April 30, 2009 from http://www.independentsector.org/programs/research/volunteer time.html.

Steele, S., Henderson, K. (1985). Partners in Action: Community Volunteers - Extension Agents: Summary of Phase I Conclusions and Implications. University of Wisconsin-Madison: Implications of Volunteerism in Extension, Department of Continuing and Vocational Education.

Volunteer Development Agency. (2006). [Online] Available at http://www.volunteering-ni.org/inform/public.asp 